\title{
Long-term patency of a RaK collagen vascular prosthesis - single centre results during a 10 year follow-up
}

\author{
Vlachovsky R, Staffa R, Gregor Z \\ 2nd Department of Surgery, St. Anne's University Hospital, and Faculty of Medicine, Masaryk University, Brno, \\ Czech Republic. robert.vlachovsky@fnusa.cz
}

\begin{abstract}
The aim of this retrospective study was to evaluate the results of vascular operations based on the RaK prostheses, with a particular attention paid to their long-term patency. The study included 105 patients who were operated on in the period from 1992 to 1996. Vascular surgery was performed in the aortofemoral area and the underlying diagnoses were Leriche syndrome, asymptomatic abdominal aortic aneurysm, iliac artery stenosis or occlusion and symptomatic abdominal aortic aneurysm. During the mean follow-up time of 96 months (range 28-144), 8 patients (7.6 \%) were lost to follow-up and 23 patients (21.9\%) died. At 12, 36, 60 and 120 months after surgery, the prostheses were patent in $99 \%, 98 \%, 93 \%$ and $89 \%$ of the patients, respectively. It is concluded that the RaK collagen prosthesis is the device of high quality and parameters comparable with the other types of knitted vascular prostheses currently used (Tab. 3, Fig. 4, Ref. 17). Full Text in PDF www.elis.sk. Key words: patency, long-term, prosthesis, vascular.
\end{abstract}

The number of different kinds of vascular prostheses that are produced today is enormous. The basic groups are distinguished according to the production technology and, to a certain extent, to the characteristic features of the prostheses - the most frequent prostheses used in vascular surgery are knitted dacron prostheses and prostheses made of an expanded polytetrafluorethylen (ePTFE).

The wall of knitted prostheses is made of synthetic fibres, most often polyester. The gradual development has led to a compromise between the porosity necessary for anchoring the internal layer of fibrin, which is gradually being deposited, and the possibility of an efficient preclotting of the prosthesis. On the other hand, a disadvantage of the prostheses that are too tightly knitted is a worse healing process and more difficult suturing. The last stage in the development of knitted prostheses is characterised by prostheses whose walls have been impregnated with collagen, gelatine or albumin during the manufacturing process. This fact ensures wall impermeability and, therefore, a minimal blood loss during implantation. Good healing is made possible by means of the gradual absorption of an artificially applied collagen layer $(1,2)$.

At the Second Department of Surgery at St. Anne's University Hospital in Brno, vascular surgery has a long tradition and has included cooperation with the producer (Výzkumný ústav pletařský Brno, Hosiery Research Institute Brno) in the research and development of synthetic grafts. At present, knitted prostheses impregnated with collagen are applied to the whole length of the

2nd Department of Surgery, St. Anne's University Hospital, and Faculty of Medicine, Masaryk University, Brno, Czech Republic

Address for correspondence: R. Vlachovsky, MD, PhD, 2nd Dept of Surgery, St. Anne's University Hospital, and Faculty of Medicine, Masaryk University, Brno, Pekarska 53, CZ-656 91 Czech Republic.

Phone: +420.543 .182431$

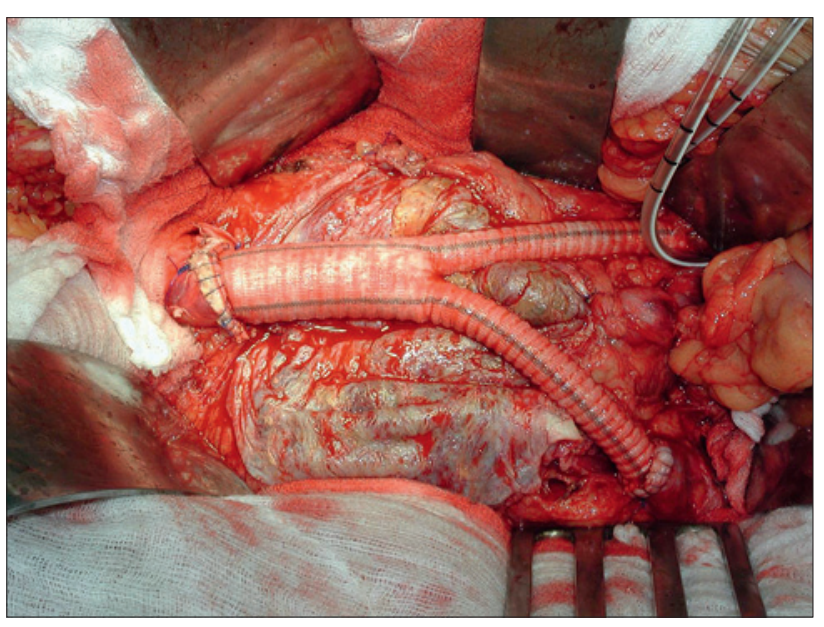

Fig. 1. Aortobiiliac graft after implantation.

abdominal aorta and iliac arteries as far as the inguinal ligament (Fig. 1). When the run-off is sufficient and it is not possible to use an autologous venous graft, they are also used in the femoropopliteal area above the knee joint.

The aim of this retrospective study was to evaluate clinical experience with this type of vascular prosthesis and to compare some relevant parameters (especially long-term patency) with the results obtained by other researchers.

\section{Materials and methods}

In our study, we have used the crimped bifurcated vascular prostheses made of polyester filament yarn using knitting technology and impregnated with bovine collagen of type I. The prosthe- 
Tab. 1. Diagnoses in patients undergoing vascular surgery.

\begin{tabular}{|c|c|c|c|c|c|}
\hline Diagnosis & Leriche syndrome & aAAA & sAAA & other aneurysms & occl./sten. CIA and EIA \\
\hline number ( $\%)$ & $\begin{array}{c}51 \\
(49.6 \%)\end{array}$ & $\begin{array}{c}18 \\
(18.6 \%)\end{array}$ & $\begin{array}{c}15 \\
(14.6 \%)\end{array}$ & $\begin{array}{c}6 \\
(5.7 \%)\end{array}$ & $\begin{array}{c}15 \\
(14.6 \%)\end{array}$ \\
\hline
\end{tabular}

aAAA - asymptomatic abdominal aortic aneurysm, sAAA - symptomatic abdominal aortic aneurysm, occl./sten. CIA and EIA - stenosis or occlusion of the common or external iliac artery

Tab. 2. Patient's risk factors.

\begin{tabular}{ll}
\hline Risk factor & Number $(\%)$ \\
\hline smoking & $66(62.8 \%)$ \\
diabetes & $44(41.9 \%)$ \\
hypertension & $54(51.4 \%)$ \\
hyperlipoproteinemia & $55(52.4 \%)$ \\
excess weight $(\mathrm{BMI}>30)$ & $24(22.9 \%)$ \\
CAD & $39(37.1 \%)$ \\
\hline
\end{tabular}

BMI - body mass index, CAD - coronary artery disease

Tab. 3. Early and late postoperative complications.

\begin{tabular}{lcc}
\hline Type of complication & $<30$ days (early) & $>30$ days (late) \\
\hline thromboembolism & $1(1 \%)$ & $8(7.6 \%)$ \\
bleeding & $2(1.9 \%)$ & - \\
superficial infection & $15(14.3 \%)$ & $3(2.9 \%)$ \\
prosthesis infection & $2(1.9 \%)$ & $3(2.9 \%)$ \\
vascular reoperation & $1(1 \%)$ & $5(4.8 \%)$ \\
compartement syndrome & $3(2.9 \%)$ & - \\
other reoperations & $12(11.4 \%)$ & $1(1 \%)$ \\
exitus & $5(4.8 \%)$ & $3(2.9 \%)$ \\
\hline
\end{tabular}

sis were used directly, without any preparation before the implantation. The patency of collagen vascular prostheses was evaluated in the group of 105 patients who met the requirements of a retrospective study, i.e., the relevant medical and personal histories were available from either records or interviews and the period of follow-up was at least 60 months. Prosthesis patency was evaluated by an objective examination (detection of pulsation, duplex ultrasound examination). The patients were examined at regular intervals at 1, 3, 6 and 12 months after surgery and then every sixth month. The state of prosthesis patency was described in medical records together with any complications; complications before postoperative day 30 were regarded as early, after day 30 , as late.

\section{Results}

\section{Patients}

Our group consisted of 105 patients (98 men, 7 women) who had the same number of vascular operations in the aortofemoral area in the years 1992-1996. The average age of the patients was 57.3 years (27-76 years). According to the Fontaine classification of ischaemic disease of the extremities, 18 patients $(17.1 \%)$ had the preoperative stage IIa, 80 patients $(76.2 \%)$ had the preoperative stage IIb, 7 patients $(6.7 \%)$ who had rest pain were classified as stage III. Table 1 shows diagnoses in patients undergoing vascular surgery; Table 2 shows risk factors.

\section{Surgical procedures and their outcome}

Before surgery, all patients had been examined and prepared by an internist (echocardiography and carotid arteries ultrasound ex- amination were mandatory); before the implantation of a vascular prosthesis, single-dose antibiotics prophylaxis was administered. Surgery was performed under a general anaesthesia via the median transperitoneal access. Three minutes before the application of vascular clamps, total heparinisation was accomplished (100 IU/ $\mathrm{kg}$ ); depending on the length of the operation, it was administered after 60 minutes again and, at the end of the operation in indicated cases, it was neutralised by protamine sulphate. However, in several patients with a bad run-off, heparin was allowed to subside spontaneously. Seventy-five patients $(71.4 \%)$ received a support medication; antiplatelet therapy (acetylsalicylic acid $100 \mathrm{mg}$ daily or clopidogrel $75 \mathrm{mg}$ daily) were given to 31 of them (29.5\%), ten patients took anticoagulation therapy $(9,5 \%)$ and $4(3.8 \%)$ were given other supportive substances (ticlopidin e.g.). Postoperative complications were either early (within 30 days of surgery) or late (after day 30) (Tab. 3). Skin and subcutaneos tissue infections (stage I and II according to Szilagyi) were the most frequent and affected 15 patients ( $14.3 \%)$. They were also associated with several reoperations, other than vascular (necrectomies of a secondary healing wound or resutures). One patient had to undergo a vascular reoperation, five patients died in the early postoperative period (at 2, 12, 16, 21, and 27 days after surgery, respectively). All the patients who died showed several risk factors and had ischaemic heart disease before the operation. Only in one patient was the cause of death directly associated with the implanted prosthesis that had become infected (stage III according to Szilagyi). Late complications were less frequent; thrombosis occurred most often ( 8 patients; $7.6 \%$ ) and resulted in the vascular reoperation in 5 patients. Skin and subcutaneos tissue infections (Szilagyi I) were treated in the out-patient department ( 3 patients). One patient operated on for Leriche syndrome died on the 38th postoperative day from peritonitis because of a pancreatic fistula. 3 late infections of a vascular prosthesis were diagnosed (Szilagyi III).

\section{Long-term patency of vascular prostheses}

During a mean follow-up time of 96 months (range 28-144), 8 patients (7.6\%) were lost to follow-up and 23 patients (21.9\%) died. Using the Kaplan-Meier analysis, the primary patency of prostheses was $97.5 \%$ after 1 year, $88 \%$ after 5 years and $85 \%$ after 10 years, the secondary patency of prostheses was $99 \%$ after 1 year, $93 \%$ after 5 years and $89 \%$ after 10 years (Fig. 2). In the study group, perioperative mortality was $4.8 \%, 5$ patients died at the average of 19 days after a vascular surgery; their average age was 69 years.

Using the Fischer's exact test, we analysed the role of risk factors in the development of obliteration of the vascular reconstruction. There was no significant difference in the presence of the selected risk factors between the patients who had or not an obliteration. 


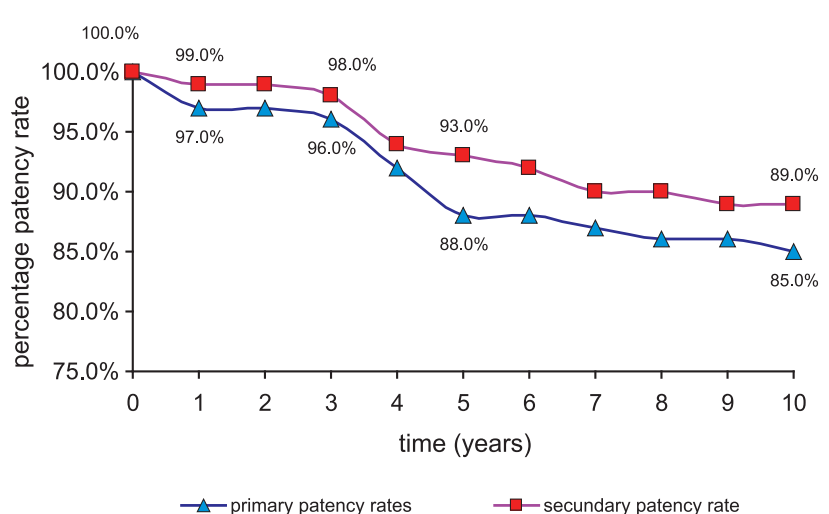

Fig. 2. Long-term patency rates.

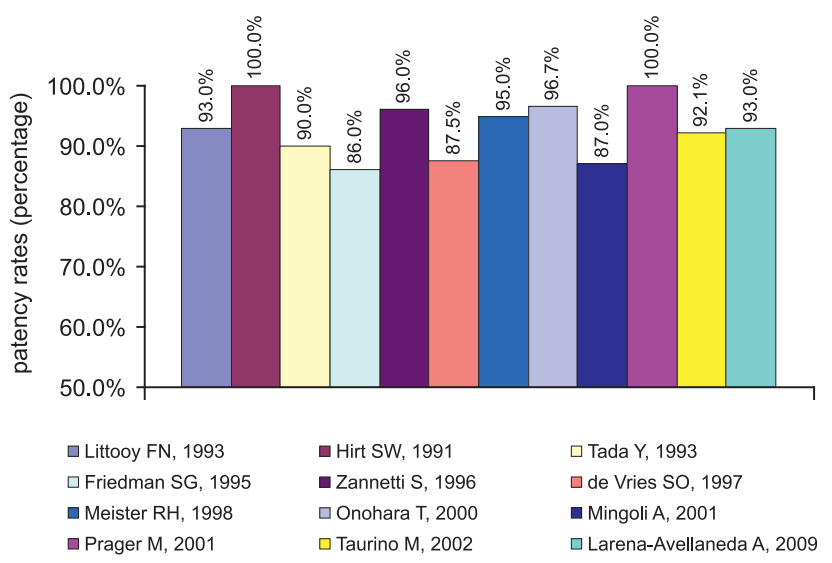

Fig. 3. 5-years secondary patency rates (literature review).

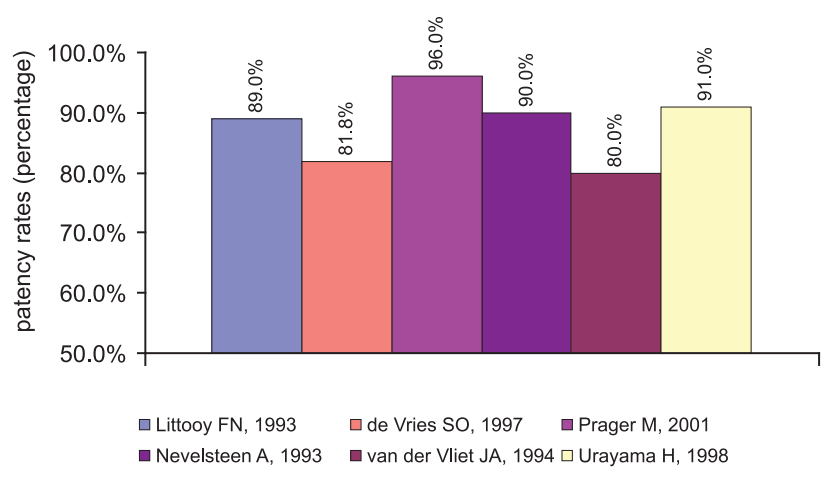

Fig. 4. 10-years secondary patency rates (literature review).

\section{Discussion}

This retrospective study included 105 patients who had the crimped collagen vascular protheses implanted in the aortofemoral area. The number of patients undergoing vascular surgery between 1992 and 1996 was, in fact, much higher but the majority of them could not be included in the group studied because they failed to come to the out-patient vascular centre for regular checkups. Therefore, the general state of patency of vascular prostheses cannot be assessed accurately, although it can be assumed that, in most cases, it was sufficient (otherwise the patients would have suffered from obliteration and would probably have come to the vascular centre). Patients with ruptured aneurysm of the abdominal aorta were not included in this study. These patients had a high postoperative mortality that did not permit a long-term follow-up of prosthesis patency; their death was not associated with prosthesis implantation but was the result of an overall severe condition. On the other hand, all the patients at risk whose death occurred due to occlusion or some other complication associated with the implantation of a synthetic vascular prosthesis, were included.

One year after the vascular surgery, the prostheses were patent in $99 \%$ of the patients; they were still patent in $93 \%$ and $89 \%$ of the patients after 5 and 10 years, respectively. In patients who had the vascular prosthesis obliteration, no involvement of risk factors such as smoking or obesity was found. This can be explained by a low number of patients studied or by the fact that the factor limiting the function of a vascular prosthesis is the state of the run-off and not smoking habits or obesity. In the past years, quite a few reports dealing with long-term patency of vascular prostheses implanted in the aortofemoral region have been published. The proportion of patients with patent prostheses 5 years after a vascular surgery ranged from $86.0 \%$ to $100.0 \%$ (3-14) (Fig. 3) and 10 years after a surgery ranged from $80.0 \%$ to $96.0 \%(3,8$, 12, 15-17) (Fig. 4). Skin and subcutaneous tissue infection (Szilagyi I), which are clinically manifested as a deteriorated healing of operation wounds, were recorded in 15 patients (14.3\%) as early complications. Their relatively frequent occurrence can be explained by the fact that more than $40 \%$ of our patients suffered from diabetes. Three late infections $(2.9 \%)$ of vascular prostheses were diagnosed.

Our long-term experience with grafts in aortoiliac and aortofemoral reconstruction shows that these prostheses have a high rate of patency and a low rate of graft-related complications and are fully comparable with the other types of knitted vascular prostheses currently used.

\section{References}

1. Mazuch J, Machan L, Bruncak P et al. Long - term results of revascularization surgery in obliterative arteriosclerosis of the lower extremities. Bratisl Lek Listy 1993; 94: 126-133.

2. Staffa R, Gregor Z, Leypold J. Pletená cévní protéza s kolagenem typu RaK - klinická zhodnocovací studie. Rozhl Chir 1998; 77: 105-109.

3. Littooy FN, Steffan G, Steinam S, Saletta C, Greisler HP. An 11year experience with aortofemoral bypass grafting. Cardiovasc Surg 1993; 1 (3): 232-238.

4. Hirt SW, Dosis D, Siclari F, Rohde R, Haverich A. Collagen-presealed or uncoated aortic bifurcation Dacron prostheses: a 5-year clinical followup study. Thorac Cardiovasc Surg 1991; 39 (6): 365-370.

5. Tada Y. Surgical treatment of arteriosclerotic arterial occlusive disease. Nippon Rinsho 1993; 51 (8): 2117-2122.

6. Friedman SG, Lazzaro RS, Spier LN, Moccio C, Tortolani AJ. A prospective randomized comparison of Dacron and polytetrafluoroethylene aortic bifurcation grafts. Surgery 1995; 117 (1): 7-10. 


\section{$15-18$}

7. Zannetti S, L'Italien GJ, Cambria RP. Functional outcome after surgical treatment for intermittent claudication. J Vasc Surg 1996; 24 (1): 65-73.

8. de Vries SO, Hunink MG. Results of aortic bifurcation grafts for aortoiliac occlusive disease: a meta-analysis. J Vasc Surg 1997; 26 (4): $558-569$

9. Meister RH, Schweiger H, Lang W. Knitted double-velour Dacron prostheses in aortobifemoral position - long-term performance of different coating materials. Vasa 1998; 27 (4): 236-239.

10. Onohara T, Komori K, Kume M, Ishida M, Ohta S, Takeuchi K, Matsumoto T, Sugimachi K. Multivariate analysis of long-term results after an axillobifemoral and aortobifemoral bypass in patients with aortoiliac occlusive disease. J Cardiovasc Surg (Torino) 2000; 41 (6): 905-910.

11. Mingoli A, Sapienza P, Feldhaus RJ, Di Marzo L, Burchi C, Cavallaro A. Comparison of femorofemoral and aortofemoral bypass for aortoiliac occlusive disease. J Cardiovasc Surg (Torino) 2001; 42 (3): 381-387.

12. Prager M, Polterauer P, Böhmig HJ, Wagner O, Fügl A, Kretschmer G, Plohner M, Nanobashvili J, Huk I. Collagen versus gelatin-coated Dacron versus stretch polytetrafluoroethylene in abdominal aortic bifurcation graft surgery: results of a seven-year prospective, randomized multicenter trial. Surgery 2001; 130 (3): 408-414.
13. Taurino M, Maggiore C, Ricci B, Rizzo L, Maraglino C, Speziale F, Fiorani P. Role of aortofemoral bypass in the management of unilateral iliac occlusive disease. A follow-up study of 95 patients over a 25 -year period. Minerva Cardioangiol 2002; 50 (2): 133-141.

14. Larena-Avellaneda A, Russmann S, Fein M, Debus ES. Prophylactic use of the silver-acetate-coated graft in arterial occlusive disease: a retrospective, comparative study. J Vasc Surg 2009; 50 (4): 790-798.

15. Nevelsteen A, Wouters L, Suy R. Aortofemoral dacron reconstruction for aorto-iliac occlusive disease: a 25 -year survey. Eur J Vasc Surg 1991; 5 (2): 179-186.

16. van der Vliet JA, Scharn DM, de Waard JW, Roumen RM, van Roye SF, Buskens FG. Unilateral vascular reconstruction for iliac obstructive disease. J Vasc Surg 1994; 19 (4): 610-614.

17. Urayama H, Ohtake H, Yokoi K, Fujimori H, Kawaguchi M, Ishikawa T, Watanabe Y. Long-term results of endarterectomy, anatomic bypass and extraanatomic bypass for aortoiliac occlusive disease. Surg Today 1998; 28 (2): 151-155. 